The Egyptian Journal of Hospital Medicine (October 2018) Vol. 73 (3), Page 6331-6336

\title{
Risk factors associated with glaucoma disease progression
}

\author{
Ahmed, Ali Yasen A, Althomali, Ibrahim Hassan M, Althobaiti, Omar Mohammed A, Assery, \\ Mohannad Solaiman Faia, Alsini, Abdullah Abdulwahab N \\ Medical school Taif University, KSA
}

\begin{abstract}
:
Background: Glaucoma is a disease which damage the eye's optic nerve. That so many instances of glaucoma can be undiscovered ways that research studies based in hospitals or specialist clinics, as an example, can be biased to specific classes of referred patients and so not representative of the Glaucoma associate. Objective: In this review we discuss risk factors that lead to onset of glaucoma and focus on risk factors affecting the progression of this disease, to give information to prevent and start early treatment. Method: PubMed and Embase database were searched up to July, 2018 for relevant studies that discussing the risk factors of glaucoma. Conclusion: The most consistent factors are older age and also higher baseline IOP. Currently, there is very little we can do about age, due to the fact that it is probably a surrogate threat factor for various other potentially more important elements, for example, mitochondrial performance. Because IOP can be lowered either medically or operatively, it is a flexible threat or prognostic element for open-angle glaucoma.
\end{abstract}

Key words: review, risk factors, glaucoma, old age, progression.

\section{Introduction:}

The variety of individuals with visual impairment in 2002 was greater than 161 million around the world, of which about 37 million were bilaterally blind ${ }^{[1]}$. After cataract glaucoma is found to be the 2nd leading root cause of loss of sight ${ }^{[2]}$. The effect of glaucoma on health-care systems is presently enhancing with aging population. In the Western world chronic openangle glaucoma (OAG) is without a doubt the most typical form of the illness. Glaucoma entails a progressive loss of retinal ganglion cells (RGC) as well as characteristic changes in neuroretinal rim tissue in the optic nerve head $(\mathrm{ONH})$ which are accompanied by visual field (VF) restriction ${ }^{[1]}$. There are numerous sorts of glaucoma comprising a team of eye illness which are the leading reason for permanent blindness around the world ${ }^{[2]}$. Besides the threat of developing glaucoma there is the risk that it is not spotted and also permanent loss of vision follows ${ }^{[1]}$. In an example of 5000 city Greek individuals over 59 years of age, $57.1 \%$ of glaucoma situations were located to be undiagnosed ${ }^{[3]}$. A research of 3654 predominantly white Australians $(90.2 \%$ over 60 years of age and $24 \%$ over 80 years of age) discovered that the occurrence of POAG was $3.0 \%$ with $51 \%$ not having been previously diagnosed ${ }^{[4]}$. That so many instances of glaucoma can be undiscovered ways that research studies based in hospitals or specialist clinics, as an example, can be biased to specific classes of referred patients and so not representative of the Glaucoma associate [5], which should preferably consist of all the undiagnosed cases. Identification of the risk variables for glaucoma advancement requires population-based studies ${ }^{[5]}$.

Rate of progression is a scientifically vital yet difficult to measure criterion in glaucoma disease management. An exact sign of rate of development of glaucomatous illness would enable clinicians to determine patients who are at the majority of threat of enduring a substantial decrease in their quality of life from the condition. In spite of numerous studies examining the methods of measuring condition progression, there is still currently little consensus with major randomised regulated trials using various approaches ${ }^{[6]}$. A major concern that avoids the precise measurement of glaucoma condition development is that it is concealed by the brief and also long-term irregularity that is inherent in visual field screening ${ }^{[7]}$. Trend based evaluation, although incomplete, enables medical professionals to 
detect refined visual field development despite considerable variability ${ }^{[8]}$. Prices of development differ significantly among people. The ordinary rate of development is between 0.3 and also $-0.5 \mathrm{~dB}$ decline in mean deviation (MD) annually and not all patients become aesthetically impaired during their lifetimes ${ }^{[9]}$. A rate of progression qualified by a decline in MD of greater than or equal to $1 \mathrm{~dB} /$ year has been considered by several research studies as the criteria for swiftly progressive illness ${ }^{[10]}$. This rate of progression is substantial as it would certainly result in development of disease from early to advance stage in the space of 10 to 15 years leading to substantial unfavorable personal and social influence ${ }^{[11]}$. A number of concepts have been proposed regarding the reasons behind glaucoma illness progression also the pathogenesis of the condition. The most widely known is the mechanical concept, where high intraocular pressure (IOP) flaws the lamina cribosa, which misshapes the nerves fibers running through it and also interferes with axoplasmic circulation ${ }^{[12]}$. This concept describes the association of intraocular threat factors such as increased IOP, IOP variation, main corneal thickness (CCT) and also corneal rigidity to glaucoma progression [10]. Nonetheless, it does not clarify why most patients with high IOP do not create glaucoma and some patients worsen despite ample IOP control ${ }^{[13]}$.

Glaucoma is a disease which could damage the eye's optic nerve. In this review we discuss about risk factors that lead to onset of glaucoma and focus on risk factors affecting the progression of this disease, to give information to prevent and start early treatment.

Methodology:

PubMed and Embase database were searched up to July, 2018 for relevant studies that discussing the risk factors of glaucoma. The following search terms were used: risk factors; glaucoma, glaucomas. Articles were restricted to those published in English language on humans.

\footnotetext{
Discussion:

Glaucoma was specified as particular glaucomatous optic nerve damages diagnosed by fellowship-trained glaucoma professionals as well as equivalent visual field loss constant with
}

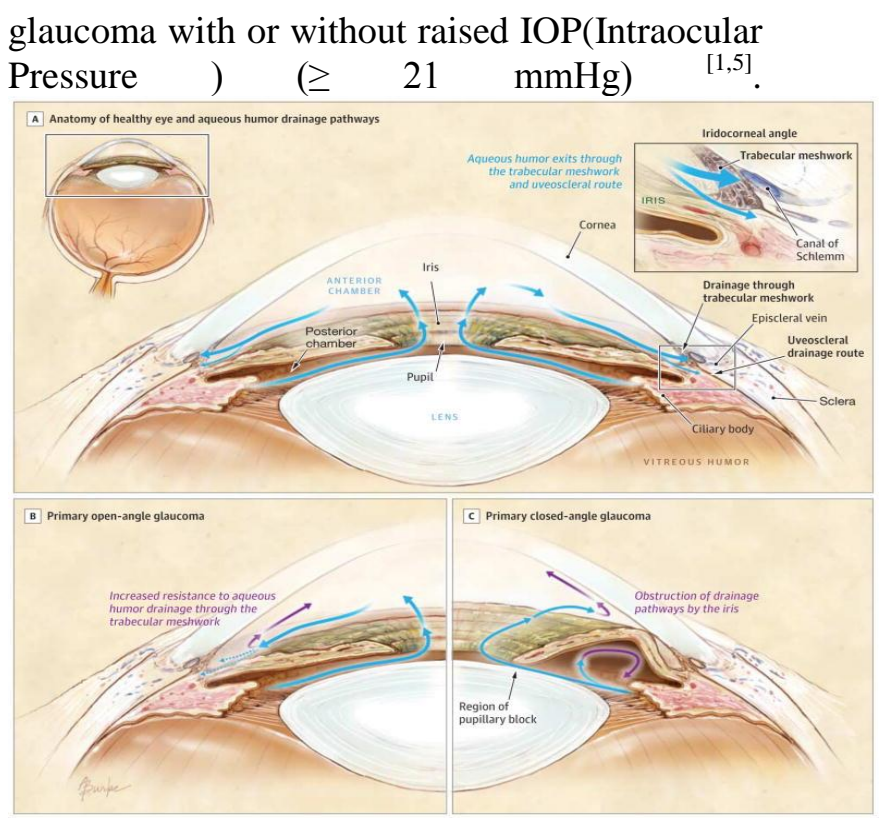

Figure 1. Aqueous Humor Drainage Pathways of Healthy and Glaucomatous Eyes

\section{- Progression from Normal to OAG (open-angle glaucoma)}

Development from the healthy condition to OAG has actually been analyzed by longitudinal population-based researches where a randomly chosen population staying in a well-defined geographical area is checked out at standard, and also re-examined after a specific time period. Incidence of conditions and also their threat elements are the major searchings for. Threat elements for the development of OAG have actually been explored in the Barbados Incidence Study of Eye Diseases (BISED), ${ }^{[14]}$ which studied an example of the African descent population in Barbados, the Melbourne Visual Impairment Project (VIP), ${ }^{[15]}$ which examined a sample of white patients in Melbourne, Australia, and in the Rotterdam Eye Study (RES), ${ }^{[16,17]}$ which studied an example of white patients in Rotterdam, Netherlands. The most relevant risk factors regularly discovered in all 3 studies are older age at baseline as well as an around $1 \mathrm{~mm} \mathrm{Hg}$ boost in IOP at baseline. In BISED and RES there was a $4 \%$ and $6 \%$, specifically, boosted threat of developing OAG in topics that were 1 year older at baseline. Baseline mean ages were 56.9 years (standard deviation [SD] 11.3) in BISED, and also 65.7 years (SD 6.9) in RES. In the VIP, where standard mean age was 58.7 years (SD 11.4), 
topics with an age of 70-79 years of ages at baseline had actually a 12-fold boosted 5-year threat of creating OAG as compared to topics aged 40-49 years of ages. In all 3 studies, there was a $10 \%$ to $14 \%$ raised risk of topics with baseline IOPs $1 \mathrm{~mm} \mathrm{Hg}$ or even more than the average for the population of creating OAG over the adhering to 5 to 9 years. The average baseline IOPs were $15.1 \mathrm{~mm} \mathrm{Hg}$ (SD 3.1) in the VIP, $18.0 \mathrm{~mm} \mathrm{Hg}$ (SD 4.1) in the BISED, and also $15.0 \mathrm{~mm} \mathrm{Hg}$ (SD 3.1) in the RES. Various other threat aspects that were found in BISED are a family history for OAG, a thinner CCT, as well as reduced ocular perfusion pressures (systemic blood pressure-IOP). The RES Table 1. Risk factors to develop Glaucoma.

\begin{tabular}{|c|c|}
\hline Age and frailty & $\begin{array}{l}\text { As is the case for glaucoma, the prevalence of lots of other health issue has the tendency to increase with } \\
\text { frailty and also might be a vital factor for their concurrence in some patients. }\end{array}$ \\
\hline Gender & $\begin{array}{l}\text { In the Ocular Hypertension Treatment (OHT) research, male gender was located by univariate evaluation } \\
\text { to be a valuable predictor for the beginning of primary open angle glaucoma (POAG) }{ }^{[18]} \text {. A Bayesian } \\
\text { meta-analysis found that males were more likely to have OAG with the reservation that gender influence } \\
\text { depends on the meaning of glaucoma }{ }^{[19]} \text {. These searchings for could just be relevant to the teams } \\
\text { researched. }\end{array}$ \\
\hline $\begin{array}{l}\text { Genetics and } \\
\text { family history }\end{array}$ & $\begin{array}{l}\text { Proof of the significance of Myocilin anomalies in innovative primary open angle glaucoma (POAG) } \\
\text { and also copy number variations of TBK1 in normal tension glaucoma (NTG) }{ }^{[17]} \text { illustrate the diagnostic } \\
\text { potential for genetic screening. However, the contribution of genes in glaucoma threat prediction has } \\
\text { usually been restricted to knowledge of family history }{ }^{[17]} \text { although, too often, patients are not aware of } \\
\text { member of the family who have actually been detected with glaucoma }{ }^{[17]} \text {. That more than } 50 \% \text { of } \\
\text { glaucoma situations can be undiagnosed adds to the unreliability of family history. }\end{array}$ \\
\hline Race & $\begin{array}{l}\text { For certain age Racette and also co-authors approximated the occurrence of POAG in a black American } \\
\text { populace, to be six times higher compared with whites }{ }^{[20]} \text {. }\end{array}$ \\
\hline Myopia & $\begin{array}{l}\text { Myopia has been discovered to be a considerable risk variable for glaucoma }{ }^{[21]} \text {. That myopia is a risk } \\
\text { aspect for glaucoma and that it is additionally much more widespread among Asian patients could aid } \\
\text { clarify raised frequency. On top of that, that high myopia and boosted axial size in particular age groups } \\
\text { have actually both been determined as risk factors recommends that the threat of glaucoma advancement } \\
\text { as well as progression rises with the degree of myopia }{ }^{[21]} \text {. }\end{array}$ \\
\hline $\begin{array}{c}\text { Systemic } \\
\text { hypotension and } \\
\text { hypertension }\end{array}$ & $\begin{array}{l}\text { Systemic high blood pressure, vasospasm, and also acute hypotension have actually been suggested as } \\
\text { potential danger variables for glaucoma in clinic-based researches }{ }^{[22]} \text {. A number of research studies have } \\
\text { actually reported associations in between reduced diastolic pressure, lower ocular perfusion stress (OPP) } \\
\text { as well as higher occurrence and/or occurrence of glaucoma }{ }^{[22]} \text {. Low systemic blood pressure (BP), } \\
\text { particularly when incorporated with a raised IOP, will certainly reduce OPP and also run the risk of a } \\
\text { reduction in the quantity of blood flow to the ONH in eyes with a damaged auto-regulatory system }{ }^{[22]} \text {, } \\
\text { causing ischaemic and also reperfusion oxidative stress and anxiety damage to the axons and connected } \\
\text { degeneration of the RGCs. A history of antihypertensive therapy and also connected lower BP might } \\
\text { enhance the threat of glaucoma by this device }{ }^{[22]} \text {. }\end{array}$ \\
\hline Vasospasm & $\begin{array}{l}\text { Vasospasm stands for vascular dysregulation connected with inappropriate constriction or not enough } \\
\text { dilatation in the microcirculation }{ }^{[23]} \text {. The eye is frequently associated with a vasospastic disorder with } \\
\text { vasospasm connected with anterior ischaemic optic neuropathy as well as glaucoma. Vasospasm is } \\
\text { frequently falsely related with Raynaud's phenomenon. Vasospasm patients usually existing with cold } \\
\text { hand signs and symptoms yet they typically do not have the pale fingers which are characteristic of } \\
\text { Raynaud's condition. Vasospasm patients regularly have low BP which, as reviewed, may likewise be } \\
\text { associated with lowered OPP and glaucoma threat }{ }^{[23]} \text {.. }\end{array}$ \\
\hline $\begin{array}{l}\text { Medication- } \\
\text { related IOP } \\
\text { elevation }\end{array}$ & $\begin{array}{l}\text { The concomitant use glaucoma as well as systemic medications for co-existing systemic problems } \\
\text { produces the potential for drug interactions, along with negative effects from both teams of medicines }{ }^{[24]} \text {. } \\
\text { As an example, ACG as a result of pupillary block can be brought on by local or systemic administration } \\
\text { of adrenergic representatives, as well as by sulfa-based medications }{ }^{[29]} \text {. Corticosteroid-induced glaucoma } \\
\text { and also OHT is a response to enhanced resistance to aqueous discharge. Therapy for systemic high blood } \\
\text { pressure or Raynaud's condition might boost the threat of glaucoma }{ }^{[25]} \text {. }\end{array}$ \\
\hline
\end{tabular}

reported an association in between using systemic calcium network blockers for the treatment of systemic high blood pressure and also the growth of OAG. The VIP reported a boosted threat of OAG in people with pseudoexfoliation, huge cup-to-disk proportions of their optic disks, or the use of systemic alphaagonist blockers. Neither the VIP neither RES determined a family history of OAG as a danger variable for OAG. Diabetic issue was not a risk factor in any one of the three research studies. Both family history of OAG and also diabetes were identified by self-report in all three researches as well as, hence, may undergo recall bias and/or measurement mistake. 


\section{- Glaucoma disease progression risk factors}

\section{Cardiovascular Disease}

Among the most striking arise from our evaluation is that CVD is a significant determinant of glaucoma condition development. The threat of having swiftly progressive condition is doubled in those with a cardiovascular background. Every one of the danger elements consisted of under the CVD umbrella in our research can either cause or are a result of poor blood flow. This fits well with the 'vascular concept' of glaucoma. Most of huge population trials that have actually been published in the literature works concentrate on the frequency and impacts of CVD in patients with glaucoma ${ }^{[26]}$, with few researches focusing on exactly how CVD actually relates to condition development. The verdicts relating to the significance of CVD as a risk element for development originated from these few studies are combined. Many studies currently available have supported no link in between cardiovascular disease history and glaucoma progression ${ }^{[27]}$.A previous research study based upon the Early Manifest Glaucoma Trial (EMGT) showed similar findings to our present research, with CVD patients having a risk ratio of 2.75 for glaucoma disease progression compared to non-CVD patients ${ }^{[28]}$. The CVD patients in the EMGT trial who progressed were more likely to have greater standard IOP compared with those that did not. This is a significant point of distinction to the conclusion derived from our current research, which revealed CVD topics that progressed had considerably reduced IOP. This observation can suggest that CVD is a strong risk aspect for fast glaucoma development, independent of IOP control, which additionally fits with the vascular concept.

\section{Intraocular Pressure}

Elevated IOP The literature is clear that high IOP is a considerable risk aspect for all forms of glaucoma, with $21 \mathrm{mmHg}$ commonly cited as the ceiling for 'normal' IOP. Sommer et al. ${ }^{[29]}$ report that for individuals with IOP between $20 \mathrm{mmHg}$ and $23 \mathrm{mmHg}$, the risk of developing glaucoma is 4 times above for individuals with IOP listed below $16 \mathrm{mmHg}$. This risk increases greatly to
10 times when the IOP is $\geq 24 \mathrm{mmHg}$, and to more than 40 times when IOP is $>30 \mathrm{mmHg}$. There is solid evidence from both the Ocular Hypertension Treatment Study as well as the Early Manifest Glaucoma Treatment Trial analysis that every $1 \mathrm{mmHg}$ rise in mean IOP level was related to a $10 \%$ raised threat of progression from ocular high blood pressure to glaucoma and in progressive glaucomatous damages ${ }^{[29]}$. If a 'typical' IOP has formerly been tape-recorded on a patient's notes or patients have actually been advised of a 'regular' IOP by an eye doctor or ophthalmologist in the past, primary healthcare suppliers must take into consideration the last day of the IOP analysis to identify whether it can reflect present threat condition (i.e. a 'typical' IOP analysis 10 years ago compared with a 'typical' IOP reading 3 months ago).

\section{Smoking}

Numerous clinicians as well as scientists think that primary open angle glaucoma has a vascular origin involving endangered blood circulation to the optic nerve head. Nonetheless, inning accordance with Bonovas et al. ${ }^{[30]}$ the proof for participation of smoking in the pathogenesis of primary open angle glaucoma is questionable. Although, several researches have shown that cigarette smoking is a threat aspect for its progression, others have cannot do so'. Six researches were included in a methodical review and meta-analysis by Bonovas et al. ${ }^{[30]}$. They reported that current cigarette smoking causes a considerable increase in the danger of primary open angle glaucoma $(\mathrm{OR}=1.37$, 95\%CI 1.00 1.87), while past cigarette smoking does not show up to influence this risk $(\mathrm{OR}=1.03,95 \% \mathrm{CI}$ 0.77-1.38). Bonovas et al. ${ }^{[30]}$ concluded that the meta-analysis searchings for sustain an organization between present cigarette smoking and primary open angle glaucoma. Nonetheless, many concerns stay, greatly because expertise regarding the biological systems of this impact is insufficient.

\section{Conclusion:}

Numerous threat, predictive, and prognostic factors for glaucoma have been reported over the past decade. One of the most consistent factors 
are older age and also higher baseline IOP. Currently, there is very little we can do about age, due to the fact that it is probably a surrogate threat factor for various other potentially more important elements, for example, mitochondrial performance. Because IOP can be lowered either medically or operatively, it is a flexible threat or prognostic element for OAG. The device of activity of IOP on OAG has actually been thoroughly researched. The look for other flexible risk or prognostic elements, such as the function of IOP change or nutritional variables, is essential since it is via alteration of these elements that we could influence the progression or advancement of OAG Cardiovascular disease is a vital predictor for swiftly progressive glaucomatous visual loss, irrespective of IOP. Emphasizes the significance of optimizing cardiovascular risk consider order to lower the threat of rapidly dynamic disease.

\section{Reference:}

1. Shon K, Wollstein G, Schuman J et al. (2014): Prediction of glaucomatous field progression: pointwise analysis. Curr Eye Res., 39:705-710.

2. Quigley H, Broman A (2006): The number of people with glaucoma world wide in 2010 and 2020. Br J Ophthalmol., 90:262-267.

3. Topouzis F, Coleman A, Harris A (2008): Factors associated with undiagnosed open-angle glaucoma: the Thessaloniki Eye Study. Am J Ophthalmol., 145:327-335.

4. Mitchell P, Smith W, Attebo K et al. (1996): Prevalence of open-angle glaucoma in Australia. Ophthalmology, 103:1661-1669.

5. Tatemichi M, Nakano $T$, Tanaka $K$ (2004): Possible association between heavy computer users and glaucomatous visual field abnormalities: a cross sectional study in Japanese workers. J Epidemiol Community Health, 58:10211027.

6. Vesti E, Johnson CA, Chauhan B (2003): Comparison of Different Methods for Detecting Glaucomatous
Visual Field Progression. Invest Ophthalmol Vis Sci., 44(9):3873-9.

7. Chauhan B, Tompkins J, LeBlanc et al. (1993): Characteristics of frequency of seeing curves in normal subjects, patients with suspected glaucoma and patients with glaucoma. Invest Ophthalmol Vis Sci., 34(13):3534-40.

8. DeMoraes C, Liebmann J, Leonard L (2017): Detection and measurement of clinically meaningful visual field progression in clinical trials for glaucoma. Prog Retin Eye Res., 56:10747.

9. Anderson D, Drance S, Schulzer M (2001): The Collaborative NormalTension Study Group. Natural History of Normal Tension Glaucoma. Ophthalmology, 108(2):247-53.

10. Saunders L, Russell R, Kirwan J et al. (2014): Examining Visual Field Loss in Patients in Glaucoma Clinics During Their Predicted Remaining Lifetime. Invest Ophthalmol Vis Sci., 55(1):102-9.

11. Heijl A, Buchholz P, Norrgren G et al. (2013): Rates of visual field progression in clinical glaucoma care. Acta Ophthalmol., 91(5):406-12.

12. Ahmad SS (2016): Controversies in the vascular theory of glaucomatous optic nerve degeneration Taiwan $\mathrm{J}$ of Ophthalmol., 6(4):182-6.

13. Weinreb $R$, Aung $T$, Medeiros $F$ (2014): The Pathophysiology and Treatment of Glaucoma. JAMA., 311(18):1901-11.

14. Leske $M$, Wu $S$, Hennis A et al. (2008): for the Barbados Eye Study Group. Risk factors for incident openangle glaucoma. The Barbados Eye Studies. Ophthalmology, 115:85-93,

15. Le A, Mukesh B, McCarty $\mathrm{C}$ et al. (2003): Risk factors associated with the incidence of open-angle glaucoma: the visual impairment project. Invest Ophthalmol Vis Sci., 44:3783-3789.

16. Souzeau E, Burdon K, Dubowsky A (2013): Higher prevalence of myocilin mutations in advanced glaucoma in comparison with less advanced disease in an Australian Disease 
Registry. Ophthalmology, 120:11351143.

17. Awadalla M, Fingert J, Roos B (2015): Copy number variations of TBK1 in Australian patients with primary openangle glaucoma. Am J Ophthamol. ,159:124-130.

18. Gordon M, Beiser J, Brandt J (2002): The Ocular Hypertension Treatment Study: baseline factors that predict the onset of primary open angle glaucoma. Arch Ophthalmol., 120:714 720.

19. Rudnicka A, Mt-Isa S, Owen C et al. (2006): Variations in primary openangle glaucoma prevalence by age, gender, and race: a Bayesian metaanalysis. Invest Ophthalmol Vis Sci., 47:4254-4261.

20. Marcus M, de Vries M, Montolio J et al. (2011): Myopia as a risk factor for open-angle glaucoma: a systematic review and metaanalysis. Ophthalmology, 1994-1998.

21. Cho H, Kee C (2014): Population-based glaucoma studies in Asians. Surv Ophthalmol., 59:434-447.

22. Topouzis F, Coleman A, Harris A (2006): Association of blood pressure status with the optic disk structure in non-glaucoma subjects: the Thessaloniki Eye Study. Am J Ophthalmol.. 142:6067.

23. Memarzadeh F, Ying-Lai M, Chung J et al. (2010): Los Angeles Latino Eye Study Group. Blood Pressure, Perfusion Pressure, and Open-Angle Glaucoma: The Los Angeles Latino Eye Study. Invest Ophthalmol Vis Sci.,51(6):28727.
24. Mitchell P, Lee AJ, Wang JJ et al. (2005): Intraocular pressure over the clinical range of blood pressure: Blue Mountains Eye Study findings. Am J Ophthalmol., 140:131-132.

25. Leske MC (1983): The epidemiology of open-angle glaucoma: a review. Am J Epidemiol., 118:166-186.

26. Memarzadeh F, Ying-Lai M, Chung J et al. (2010): Blood Pressure, Perfusion Pressure, and Open-Angle Glaucoma: The Los Angeles Latino Eye Study. Invest Ophthalmol Vis Sci.,51(6):28727.

27. Feraru C, Chiselita D, Pantalon A (2016): Long-term progression and risk factors in primary open angle glaucoma in clinical care. Spektrum Augenheilkd., 30(4):181-9.

28. Cristina L M, Heijl A, Hyman L et al. (2007): Predictors of Long-term Progression in Early Manifest Glaucoma Trial. Ophthalmology, 114(11):1965-72.

29. Friedman DS, Wilson MR, Liebmann JM et al. (2004): An evidence-based assessment of risk factors for the progression of ocular hypertension and glaucoma. Archives of Ophthalmology, 138: S19-S31.

30. Bonovas S, Filioussi K, Tsantes A et al. (2004): Epidemiological association between cigarette smoking and primary open-angle glaucoma: a metaanalysis. Public Health, 118: 256-261. 